\title{
ANALISIS ASPEK-ASPEK KUALITAS SKEMA DATABASE KING AKOR'S SRAGEN
}

\author{
Andhika Wisnu Widyatama ${ }^{1)}$, Rizky Arya Kurniawan ${ }^{2)}$, Hani Setiani ${ }^{3)}$, Muh Wal Ikram ${ }^{4)}$, \\ Muhammad Noor Arridho ${ }^{5)}$, Alvian Trias Kurniawan ${ }^{6)}$, Ema Utami ${ }^{7)}$ \\ 1),2,3,4,4),5,6),7) Teknik Informatika Universitas AMIKOM Yogyakarta

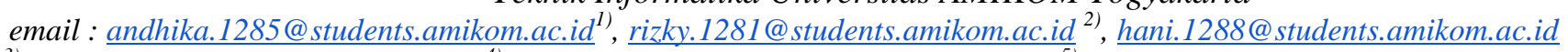 \\ 3), muh.1293@students.amikom.ac.id ${ }^{4)}$, muhammad.1297@students.amikom.ac.id $^{5)}$, alvian.1322@students.amikom.ac.id $^{7}$ \\ ${ }^{6)}, \underline{\text { ema.u@amikom.ac.id }}^{7)}$
}

\begin{abstract}
Abstraksi
Peran basis data dalam sistem informasi adalah membantu pengelolaan data untuk pengambilan keputusan. Salah satu faktor penentu keberhasilan dalam pengambilan keputusan yaitu kualitas data. Adapun dimensi dari kualitas data yang akan diteliti pada kali ini adalah aspek kemampuan dibaca, agar terwujud kualitas data yang baik perlu dilakukan pengukuran apakah skema basis data dapat dijelaskan dan mudah di pahami. Analisis yang dilakukan pada King's Akor Sragen menunjukan bahwa dengan mengidentifikasi permasalahan aspek kemampuan dibaca, maka penelitian ini menghasilkan kualitas skema basis data yang dimiliki sudah memenuhi kriteria tersebut. sehingga memudahkan teknisi baru untuk melakukan pengembangan sistem.
\end{abstract}

\section{Kata Kunci :}

aspek kualitas, skema database, penjualan

\begin{abstract}
The role of databases in information systems is to help manage data for decision-making. One of the critical success factors in decision-making is data quality. The dimensions of data quality that will be examined at this time are the aspect of readability, to realize good data quality it is necessary to measure whether the database scheme can be explained and easy to understand. The analysis carried out on the store King Akors from Sragen shows that by identifying problems in the legibility aspect, this research results in the quality of the database schema that meets these criteria. making it easier for new technicians to carry out system development
\end{abstract}

\section{Keywords :}

aspects of quality, database schema, sales

\section{Pendahuluan}

Perkembangan teknologi informasi saat ini terus meningkat seiring dengan berjalannya waktu pada semua bidang. Salah satunya adalah King's Akor yang merupakan perusahaan yang bergerak dibidang furniture. maka informasi yang telah terkomputerisasi memiliki ukuran penyimpanan yang lebih kecil dan kecepatan akses yang cepat sehingga memudahkan serta mempersingkat waktu pengguna untuk mencari informasi yang dibutuhkan. Dari sekian banyak informasi yang beredar tentu tak lepas dari proses penyimpan yang ada. salah satu media penyimpanan yang digunakan adalah sebuah database.

Sehingga database memiliki peran sebagai sumber informasi harus mampu memenuhi kebutuhan penggunanya. Dalam rancangan skema database dibutuhkan kualitas agar tercapainya tingkat keberhasilan serta mengurangi permasalahan yang ada dalam sistem informasi.

Perancangan database yang dilakukan tanpa perencanaan yang tepat akan menimbulkan terjadinya inkonsistensi data, redudansi data dan ketidaksesuaian struktur data, sehingga menyebabkan data sulit untuk dikelola dan berakibat fatal terhadap hasil akhirnya [1].

Pada dasarnya ada banyak aspek-aspek yang membahas tentang kualitas database, terdapat 9 (sembilan) aspek kriteria kualitas sebuah database antara lain aspek kebenaran, aspek konsistensi, aspek relevansi, aspek jangkauan, aspek tingkat detail, aspek kelengkapan, aspek minimalitas, aspek kemampuan integrasi, dan aspek kemampuan dibaca [2].

Penelitian ini akan membahas analisis kualitas basis data tentang aspek kemampuan dibaca/readability pada database King's Akor Sragen, dengan tujuan untuk mengetahui kualitas skema basis data pada sistem tersebut sesuai dengan kriteria-kriteria yang ditetapkan sehingga memudahkan para pengembang sistem dalam memahami alur sistem yang sudah dibuat sebelumnya. 


\section{Tinjauan Pustaka}

Didalam suatu penelitian yang membahas kualitas informasi menjadi suatu hal yang sangat penting dalam beberapa tahun terakhir. Hal ini dapat terlihat dari para peminat yang terus meningkat. Pada penelitian D.D. Cowan dkk menerangkan membaca dan memahami program menjadi aktivitas kunci, kemampuan orang untuk memahami program secara langsung berkaitan dengan kemudahan dalam membaca dokumentasi kode sumbernya. penggunaan markup bahasa seperti SGML menyematkan syntax dan semantik dari kode suatu program. ini menunjukkan bagaimana ini dapat digunakan untuk meningkatkan gaya presentasinya [3].

Menurut kadir (2008), basis data atau database merupakan koleksi data yang saling terkait. singkatnya, basis data sebagai suatu penyusun data yang terstruktur lalu disimpan dalam media pengingat (harddisk) yang tujuannya adalah agar data tersebut dapat diakses dengan mudah dan cepat. Menurut Priyadi, Y. (2014), basis data merupakan kumpulan fakta-fakta yang berupa representasi tabel yang saling berkaitan disimpan pada media penyimpanan secara digital. Sekumpulan tabel yang saling berelasi maupun tidak berelasi adalah bagian dari basis data. semua tabel tersebut merupakan representasi tempat untuk menyimpan data yang berfungsi sebagai pendukung basis data pada sebuah sistem.

Olaf Herden (2001) menerapkan meta model dalam mengukur aspek-aspek kualitas skema berorientasi objek (object oriented), pada penelitiannya didapat suatu usulan untuk meninjau terlebih dahulu database tersebut berdasarkan beberapa aspek yang sudah ditetapkan yang terdiri atas 9 (sembilan) kriteria, antara lain:

$\begin{array}{ll}\text { 1. } & \text { Kebenaran (correctness) } \\ 2 . & \text { Kelengkapan (completeness) } \\ \text { 3. } & \text { Jangkauan (scope) } \\ \text { 4. } & \text { Konsistensi (consistency) } \\ 5 . & \text { Relevansi (relevance) } \\ 6 . \quad \text { Tingkat detail (level of detail) } \\ \text { 7. } \quad \text { Minimalitas (minimality) } \\ \text { 8. } \quad \text { Kemampuan untuk diintegrasikan (ability } \\ \text { of integration) } \\ 9 . \quad \text { Kemampuan untuk dibaca (readability) }\end{array}$

9. Kemampuan untuk dibaca (readability).

Dalam pelaksanaannya dilakukan pada database akademik di ISTA. adapun analisis yang dilakukan mencakup perancangan logika, penggunaan teknologi perangkat keras, maupun perangkat lunak serta menerapkan model logika berupa bussiness rule.

\section{Metode Penelitian}

Di Bagian ini akan membahas langkah-langkah yang akan dilakukan pada penelitian ini yang diawali dengan identifikasi masalah, pengumpulan data, analisis data dan diakhiri dengan kesimpulan serta saran. Metodologi adalah satuan metode-metode, prosedur-prosedur, konsep-konsep pekerjaan, aturan-aturan dan postulat-postulat yang digunakan oleh suatu ilmu pengetahuan, seni atau disiplin lainnya.

Pada metode penelitian akan dijelaskan mengenai langkah-langkah dalam menyelesaikan permasalahan yang dibahas, agar mendapatkan hasil yang optimal.

Aspek kemampuan dibaca merupakan aspek yang penting karena dapat digunakan untuk melakukan pengukuran apakah semua istilah dalam skema database bisa dijelaskan dan bisa dipahami. Untuk dapat melakukan pengujian terhadap sebuah database maka kita harus mengetahui terlebih dahulu apa saja kriteria dari aspek kualitas kemampuan dibaca. Berikut adalah kriteria-kriteria aspek kemampuan untuk dibaca [4] :

a. Dictionary Existence, apakah kata atau penamaan atribut dan entitas dapat ditemukan dalam WordNet. Artinya penggunaan nama harus global secara bahasa.

b. Consistent Naming, gaya penamaan konsisten misalnya hanya huruf besar, huruf besar awal, huruf kecil, huruf unta, dengan atau tanpa kosong dan / atau tanda hubung.

c. Hypernyms, penggunaan kata-kata umum yang mana maksud dari kata tersebut mencakup bagian dari kata lain (subdivisi / jenis / bawahan) contohnya : kata "bunga" merupakan hypernyms dari kata mawar ataupun melati yang mana katakata ini termasuk ke dalam kategori bunga

d. Synonym, Jika terdapat suatu kata dimana kata tersebut memiliki frase ataupun maksud yang berarti persis atau hampir sama dengan kata lainnya. Contohnya: kata panjang dan diperpanjang dalam konteks waktu lama atau waktu yang diperpanjang adalah sinonim

e. Dates, istilah "tanggal" muncul di nama atribut, tipe datanya harus berupa tipe data $\boldsymbol{D A T E}$.

f. Identifier, Jika terdapat istilah "ID" atau "Identifier" muncul dalam nama atribut, atribut harus berupa kunci utama atau setidaknya unik.

g. Foreign Key, pada kriteria Foreign Key penamaan foreign key dan primary key yang saling berelasi harus sama. 


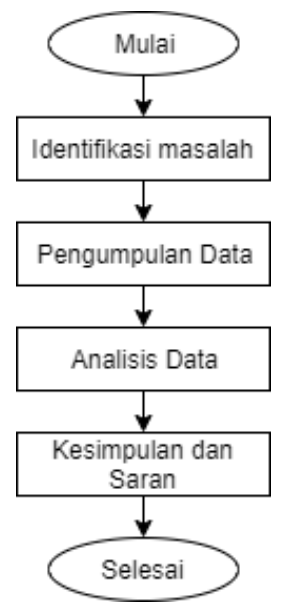

Gambar 1. Alur Penelitian

1. Identifikasi Masalah

Pada tahap ini dilakukan proses untuk mencari dan menentukan akar permasalahan terhadap objek yang akan diteliti.

2. Pengumpulan Data

Dalam tahap pengumpulan data dilakukan proses pengumpulan data yang dibutuhkan sebagai bahan penelitian dari skema database King Akor's.

3. Analisis Data

Selanjutnya analisis data dilakukan dengan menganalisis atribut beserta tabel-tabel yang berelasi di dalam database tersebut dengan berpacu kepada kriteria-kriteria aspek kemampuan dibaca.

4. Kesimpulan dan Saran

Merupakan langkah akhir dalam proses penelitian yang akan memberikan ringkasan singkat mengenai aspek kualitas skema database yang telah diteliti.

\section{Hasil dan Pembahasan}

Berdasarkan analisis yang telah dilakukan sebelumnya didapatkan hasil analisis berdasarkan kriteria dari aspek kemampuan untuk dibaca. Berikut adalah skema database King's Akor. Database tersebut digunakan untuk melakukan transaksi jual beli furniture. Terdapat 12 tabel yang saling berelasi.

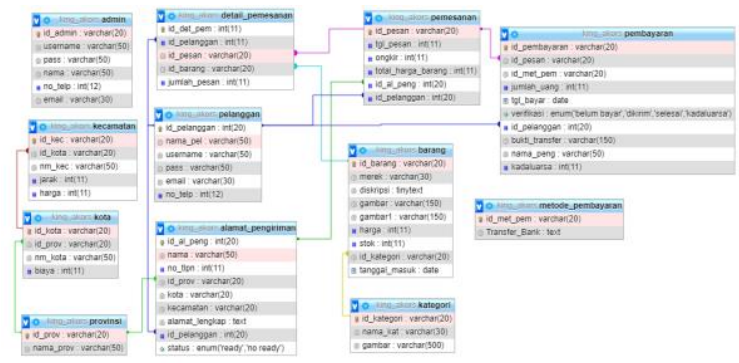

Gambar 2. Skema Database relasional King's Akor

Untuk menganalisa aspek kemampuan dibaca dari skema database King's Akor maka kita dapat melakukan analisa terhadap kriteria-kriteria berikut :

\section{Dictionary Existence}

Kriteria dictionary existence mengharuskan skema database menggunakan nama entitas yang dapat ditemukan di WordNet. Berikut adalah entitas pada skema database King's Akor

Tabel 1. Entitas Skema Basis Data King's Akor

\begin{tabular}{|l|l|l|}
\hline \multicolumn{1}{|c|}{ No } & \multicolumn{1}{|c|}{ Entitas } & \multicolumn{1}{c|}{ Valid } \\
\hline 1 & admin & Ya \\
\hline 2 & pelanggan & Ya \\
\hline 3 & alamat_pengiriman & Ya \\
\hline 4 & kecamatan & Ya \\
\hline 5 & kota & Ya \\
\hline 6 & provinsi & Ya \\
\hline 7 & pemesanan & Ya \\
\hline 8 & detail_pemesanan & Ya \\
\hline 9 & pembayaran & Ya \\
\hline 10 & metode_pembayaran & Ya \\
\hline 11 & barang & Ya \\
\hline 12 & kategori & Ya \\
\hline
\end{tabular}

\section{Consistent Naming}

Gaya penamaan pada skema basis data King's Akor adalah menggunakan gaya penulisan snake case. Gaya penulisan tersebut ditandai dengan menggunakan garis bawah atau underscore (_). Kemudian gaya penulisan menggunakan huruf kecil. Dapat dilihat pada Tabel 1 bahwa entitas pada skema basis data King's Akor sudah konsisten.

\section{Hypernyms}

Terdapat penggunaan beberapa kata umum pada database tersebut, untuk penjelasan lebih lanjut sebagai berikut.

Tabel 2. Analisis Kriteria Hypernym

\begin{tabular}{|l|l|l|l|}
\hline No & Tabel & Hyperyms & \multicolumn{1}{|c|}{ Turunan } \\
\hline 1 & Kota & nm_kota & $\begin{array}{l}\text { Semarang, Solo, } \\
\text { Madiun dll }\end{array}$ \\
\hline 2 & Provinsi & nm_prov & $\begin{array}{l}\text { Bengkulu, Aceh, } \\
\text { Banten dll }\end{array}$ \\
\hline 3 & Barang & merek & $\begin{array}{l}\text { Olympic, Ikea, } \\
\text { Informa dll }\end{array}$ \\
\hline 4 & Kategori & nama_kat & $\begin{array}{l}\text { Lemari, Kursi, Meja } \\
\text { dll }\end{array}$ \\
\hline
\end{tabular}

\section{Synonym}


- Atribut nm_pel pada tabel pelanggan dan nama pada tabel pengiriman.

- Atribut nm_kota pada tabel kota dan kota pada tabel pengiriman.

- Atribut nm_kec pada tabel kota dan kecamatan pada tabel pengiriman.

- Atribut no_telp pada tabel admin dan no_telp pada tabel pelanggan.

- Atribut username, password, email pada tabel admin dan tabel pelanggan.

- Atribut gambar pada tabel barang tabel kategori.

\section{Dates}

Apabila terdapat istilah "tanggal" yang muncul di nama atribut, tipe datanya harus berupa tipe data DATE. Pada skema database King's Akor terdapat beberapa atribut yang menggunakan istilah tanggal.

Tabel 3. Analisis Kriteria Dates

\begin{tabular}{|l|l|l|l|l|}
\hline No & $\begin{array}{l}\text { Nama } \\
\text { Tabel }\end{array}$ & $\begin{array}{l}\text { Atribu } \\
\mathbf{t}\end{array}$ & $\begin{array}{l}\text { Tipe } \\
\text { Data }\end{array}$ & Valid \\
\hline 1 & pemesanan & $\begin{array}{l}\text { tgl_pes } \\
\text { an }\end{array}$ & int (11) & Tidak \\
\hline 2 & barang & $\begin{array}{l}\text { tanggal } \\
\text { masuk }\end{array}$ & date & Ya \\
\hline 3 & $\begin{array}{l}\text { pembayara } \\
\text { n }\end{array}$ & $\begin{array}{l}\text { tgl_bay } \\
\text { ar }\end{array}$ & date & Ya \\
\hline
\end{tabular}

Pada hasil analisis pada Tabel 3 di atas terdapat 3 tabel yang menggunakan istilah "tanggal". Namun dalam implementasinya terdapat satu tabel yaitu tabel pemesanan dengan nama atribut tgl_pesan masih menggunakan tipe data int (11). Maka hal tersebut menyimpang dari aturan kriteria dates. Untuk itu dianjurkan untuk mengubah tipe data menjadi date.

\section{Identifier}

Jika terdapat istilah "ID" atau "Identifier" muncul dalam nama atribut, atribut harus berupa kunci utama atau setidaknya unik. Berikut nama-nama atribut yang merupakan kunci primer atau identifier.

Tabel 4. Identifier Skema Basis Data King's Akor

\begin{tabular}{|l|l|l|}
\hline No & \multicolumn{1}{|c|}{$\begin{array}{c}\text { Identifier / Kunci } \\
\text { Primer }\end{array}$} & \multicolumn{1}{c|}{ Unique } \\
\hline 1 & admin & Ya \\
\hline 2 & pelanggan & Ya \\
\hline 3 & alamat_pengiriman & Ya \\
\hline 4 & kecamatan & Ya \\
\hline 5 & kota & Ya \\
\hline 6 & provinsi & Ya \\
\hline
\end{tabular}

\begin{tabular}{|l|l|l|}
\hline \multicolumn{1}{|c|}{ No } & \multicolumn{1}{|c|}{$\begin{array}{c}\text { Identifier/Kunci } \\
\text { Primer }\end{array}$} & \multicolumn{1}{c|}{ Unique } \\
\hline 7 & pemesanan & Ya \\
\hline 8 & detail_pemesanan & Ya \\
\hline 9 & pembayaran & Ya \\
\hline 10 & metode_pembayaran & Ya \\
\hline 11 & barang & Ya \\
\hline 12 & kategori & Ya \\
\hline
\end{tabular}

\section{Foreign Key}

Penamaan foreign key dan primary key yang saling berelasi harus sama. Jika dilihat pada gambar 1 maka dapat dilihat relasinya sebagai berikut :

Tabel 5. Analisis Kriteria Foreign Key

\begin{tabular}{|c|c|c|c|}
\hline No & $\begin{array}{l}\text { Primary } \\
\text { Key }\end{array}$ & Foreign Key & Valid \\
\hline \multirow[t]{2}{*}{1} & $\begin{array}{l}\text { Tabel } \\
\text { Kota }\end{array}$ & $\begin{array}{c}\text { Tabel } \\
\text { Kecamatan }\end{array}$ & \multirow[t]{2}{*}{$\mathrm{Ya}$} \\
\hline & id_kota & id_kota & \\
\hline \multirow[t]{2}{*}{2} & $\begin{array}{c}\text { Tabel } \\
\text { provinsi }\end{array}$ & $\begin{array}{l}\text { Tabel } \\
\text { Kota }\end{array}$ & \multirow[t]{2}{*}{$\mathrm{Ya}$} \\
\hline & id_prov & id_prov & \\
\hline \multirow[t]{2}{*}{3} & $\begin{array}{l}\text { Tabel } \\
\text { Provinsi }\end{array}$ & $\begin{array}{l}\text { Tabel } \\
\text { alamat_pengiri } \\
\text { man }\end{array}$ & \multirow[t]{2}{*}{$\mathrm{Ya}$} \\
\hline & id_prov & id_prov & \\
\hline \multirow[t]{2}{*}{4} & $\begin{array}{l}\text { Tabel } \\
\text { Pelanggan }\end{array}$ & $\begin{array}{l}\text { Tabel } \\
\text { alamat_pengiri } \\
\text { man }\end{array}$ & \multirow[t]{2}{*}{ Ya } \\
\hline & id_pelanggan & id_pelanggan & \\
\hline \multirow[t]{2}{*}{5} & $\begin{array}{l}\text { Tabel } \\
\text { Pelanggan }\end{array}$ & $\begin{array}{l}\text { Tabel } \\
\text { detail_pemesa } \\
\text { nan }\end{array}$ & \multirow[t]{2}{*}{$\mathrm{Ya}$} \\
\hline & id_pelanggan & id_pelanggan & \\
\hline \multirow[t]{2}{*}{6} & $\begin{array}{l}\text { Tabel } \\
\text { Pelanggan }\end{array}$ & $\begin{array}{l}\text { Tabel } \\
\text { pemesanan }\end{array}$ & \multirow[t]{2}{*}{$\mathrm{Ya}$} \\
\hline & id_pelanggan & id_pelanggan & \\
\hline
\end{tabular}




\begin{tabular}{|c|c|c|c|}
\hline No & $\begin{array}{l}\text { Primary } \\
\text { Key }\end{array}$ & Foreign Key & Valid \\
\hline \multirow[t]{2}{*}{7} & $\begin{array}{l}\text { Tabel } \\
\text { Pelanggan }\end{array}$ & $\begin{array}{l}\text { Tabel } \\
\text { pembayaran }\end{array}$ & \multirow[t]{2}{*}{ Ya } \\
\hline & id_pelanggan & id_pelanggan & \\
\hline \multirow[t]{2}{*}{8} & $\begin{array}{l}\text { Tabel } \\
\text { alamat_pengi } \\
\text { riman }\end{array}$ & $\begin{array}{l}\text { Tabel } \\
\text { Pemesanan }\end{array}$ & \multirow[t]{2}{*}{$\mathrm{Ya}$} \\
\hline & id_al_peng & id_al_peng & \\
\hline \multirow[t]{2}{*}{9} & Tabel barang & $\begin{array}{l}\text { Tabel } \\
\text { detail_pemesa } \\
\text { nan }\end{array}$ & \multirow[t]{2}{*}{$\mathrm{Ya}$} \\
\hline & id_barang & id_barang & \\
\hline \multirow[t]{2}{*}{10} & $\begin{array}{l}\text { Tabel } \\
\text { kategori }\end{array}$ & Tabel barang & \multirow[t]{2}{*}{$\mathrm{Ya}$} \\
\hline & id_kategori & id_kategori & \\
\hline \multirow[t]{2}{*}{11} & $\begin{array}{l}\text { Tabel } \\
\text { pemesanan }\end{array}$ & $\begin{array}{l}\text { Tabel } \\
\text { detail_pemesa } \\
\text { nan }\end{array}$ & \multirow[t]{2}{*}{$\mathrm{Ya}$} \\
\hline & id_pesan & id_pesan & \\
\hline \multirow[t]{2}{*}{12} & $\begin{array}{l}\text { Tabel } \\
\text { pemesanan }\end{array}$ & $\begin{array}{l}\text { Tabel } \\
\text { pembayaran }\end{array}$ & \multirow[t]{2}{*}{$\mathrm{Ya}$} \\
\hline & id_pesan & id_pesan & \\
\hline
\end{tabular}

Dari hasil analisis pada kriteria foreign key didapatkan hasil bahwa atribut yang saling berelasi memiliki nama atribut yang sama. Sebagai contoh pada tabel kota memiliki primary key id_kota yang berelasi dengan tabel kecamatan dengan foreign key bernama id_kota. Maka dapat disimpulkan untuk kriteria foreign key skema database King's Akor sudah memenuhi syarat.

Dari pengujian yang telah dilakukan menggunakan 7 kriteria diatas maka didapatkan hasil sebagai berikut

Tabel 6. Hasil analisis skema database

\begin{tabular}{|l|l|l|}
\hline No & Kriteria & Valid \\
\hline 1 & Dictionary Existence & Ya \\
\hline 2 & Consistent Naming & Ya \\
\hline 3 & Hypernyms & Ya \\
\hline
\end{tabular}

\begin{tabular}{|l|l|l|}
\hline No & Kriteria & Valid \\
\hline 4 & Synonym & Ya \\
\hline 5 & Dates & Tidak \\
\hline 6 & Identifier & Ya \\
\hline 7 & Foreign Key & Ya \\
\hline
\end{tabular}

Dapat dilihat bahwa dari 7 pengujian kriteria kemampuan dibaca hanya terdapat 1 kriteria saja yang tidak lolos uji kriteria yaitu kriteria dates. Maka dapat dihitung tingkat kesesuaian skema database King's Akor sebagai berikut :

Tingkat kesesuaian $=6 / 7 \times 100$

$$
=85,7 \%
$$

\section{Kesimpulan dan Saran}

Penelitian ini berhasil melakukan analisis terhadap aspek kemampuan dibaca pada skema basis data King's Akor Sragen. Berdasarkan hasil analisis, secara umum dapat dinyatakan bahwa skema database King's Akor Sragen masih memiliki tingkat kesesuaian 85,7\%. Dengan begitu akan berdampak pada proses pengembangan database yang dilakukan oleh seorang pengembang lain. Maka dari itu, perlu dilakukan upaya penyempurnaan untuk menghindari timbulnya permasalahan yang lebih kompleks dan sulit ditangani.

\section{Daftar Pustaka}

[1] T. Sharma, M. Fragkoulis, S. Rizou, M. Bruntink, and D. Spinellis, "Smelly relations: Measuring and understanding database schema quality," Proc. - Int. Conf. Softw. Eng., pp. 55-64, 2018, doi: 10.1145/3183519.3183529.

[2] O. Herden, "Measuring Quality of Database Schemas by Reviewing - Concept , Criteria and Tool," ECOOP Work. Quant. Approaches ObjectOriented Softw. Eng. (QAOOSE 2001), pp. 1-12, 2001.

[3] D.D Cowan, D.M German, D.J.P Lucena, A. Von Staa, "Enhancing Code for Readability and Comprehension Using SGML" International Conference on Software Maintenance (ICSM), doi: 10.1109/ICSM.1994.336776

[4] L. Ehrlinger, B. Werth, and W. Wöß, "Automated Continuous Data Quality Measurement with QuaIIe," Int. J. Adv. Softw., vol. 11, no. $3 \& 4$, pp. 400-417, 2018. 